\title{
Depression, elaboration, and mood congruence: Differences between natural and induced mood
}

\author{
SHERRI J. KWIATKOWSKI and STANLEY R. PARKINSON \\ Arizona State University, Tempe, Arizona
}

\begin{abstract}
The results of two experiments examining the effects of depressed mood on recall of target words and recall of descriptor words are reported. Descriptors were either negatively valenced or neutral and were not related semantically to target adjectives. There was no overall difference in the recall of targets by naturally depressed and nondepressed subjects. There was a mood $\times$ descriptor interaction on target recall, and depressed subjects recalled more negative descriptors than did nondepressed subjects. In contrast, when a depressed mood was induced through a Velten Mood Induction Procedure, induced-depressed subjects recalled fewer target words than did nondepressed subjects, and there was no differential recall of descriptor words by induced-depressed and nondepressed subjects. The results of these experiments indicate clear differences in the recall patterns of naturally depressed and induced-depressed subjects in a single cognitive task.
\end{abstract}

During recent years, there has been a surge of interest in exploring the effects of emotion on cognitive processes (Blaney, 1986; Bower, 1987; Singer \& Salovey, 1988). Within this domain an area that has received considerable attention is the influence of mood and emotion on memory (cf. Baddeley, 1990; Bower, 1981; Challis \& Krane, 1988; Ellis \& Hunt, 1989; Lazarus, 1982; Leight \& Ellis, 1981). To a great extent, the experimental analysis of affect and memory has depended on the ability to control and manipulate mood in the laboratory.

Mood has been manipulated through a variety of means, such as hypnosis (Bower, 1981), imagery (Sirota, Schwartz, \& Kristeller, 1987), odors (Ehrlichman \& Halpern, 1988), video (Pruitt \& Ferraro, 1989), and music (Sutherland, Newman, \& Rachman, 1982). The Velten (1968) Mood Induction Procedure has been used most extensively to induce depressed moods in an experimental setting. The effectiveness of this procedure has received considerable support (Kenealy, 1986). While this procedure has been shown to be effective in inducing moods, it is not clear whether mood induction represents a state similar to clinical depression (Goodwin \& Williams, 1982), mild naturally occurring depression (Clark, 1983), or some combination of moods (Polivy, 1981). This issue is further complicated by asking whether performance differences are comparable across different subject populations (e.g., induced vs. natural depression), or if ob-

The research reported here was supported by the Department of Psychology, Arizona State University. We sincerely thank the reviewers for helpful comments on earlier versions of this paper. Special thanks are due Jeanie Louthan for her assistance in preparing the stimulus set and Jennifer Krull for her support and editing skills in preparing the final paper. Correspondence concerning this article should be sent to S. Kwiatkowski, Department of Psychology, Arizona State University, Tempe, AZ 85287-1104.

-Accepted by previous editor, Margaret Jean Intons-Peterson served differences depend on the type of task used to assess the effects of depression (e.g., level of cognitive effort required; Ellis, 1990).

The importance of these issues is highlighted by some inconsistencies in results of experiments using naturally depressed and induced-depressed subjects. Ellis, Thomas, and Rodriguez (1984) conducted a series of experiments in which they compared performances of induced-depressed and nondepressed subjects on a series of semantic recall tasks, including elaborative encoding. In their elaborative encoding task, recall of target words embedded in contextually rich elaborated sentences was compared with recall of target words in unelaborated, or base, sentences. Subjects who experienced mood-induced depression consistently demonstrated poorer recall than did subjects in a neutral mood.

Ellis et al. (1984) interpreted the differences between induced-depressed and nondepressed subjects' performance in terms of a limited capacity model of attention (cf. Kahneman, 1973) in which central processing resources available for allocation to any given task are limited. Ellis et al. held that depressed mood may generate processing activities that are irrelevant to the criterion task and that preempt some of the available capacity that would otherwise be directed toward relevant features of the task. Ellis and his colleagues have replicated the basic finding of poorer recall by induced-depressed subjects with a variety of different experimental procedures (cf. Ellis, 1985; Ellis, Seibert, \& Herbert, 1990; Ellis, Thomas, McFarland, \& Lane, 1985; Leight \& Ellis, 1981).

In contrast, Hasher, Rose, Zacks, Sanft, and Doren (1985) found no evidence for an overall reduction in recall for story content with naturally mildly depressed college students as classified according to Beck Depression Inventory (BDI) scores. Hasher et al. concluded that overall recall deficits associated with depression are limited to studies in which mood is induced or in which natural 
mood states are more severe, as in cases of clinical depression. Furthermore, they concluded that their data with mildly naturally depressed subjects offered no evidence for a limited capacity view of depression.

Ellis (1985) argued that the results of Hasher et al. could be readily accommodated within a limited capacity framework. First, Ellis suggested that mood classifications based on depression inventories (e.g., the BDI) reflect mild mood conditions that may be too weak to have any evident effects on recall. Second, Ellis maintained that their task, involving logically structured prose, may have been insufficiently demanding to evidence effects of reduced capacity. It remains unclear at this point whether or not observed overall differences in recall performance are a function of type of depression (i.e., natural mild depression or induced depression), of specific aspects of different tasks, or both.

In addition to finding no overall recall differences between nondepressed and naturally depressed subjects, Hasher et al. (1985) found no mood-congruent learning effects for recall of affective content. These null findings for mood congruence resemble other findings with naturally depressed subjects (Gotlib \& McCann, 1984; Pietromonaco \& Markus, 1985). Mood-congruent learning effects are often found in comparisons between neutral and induced-depressed subjects (cf. Blaney, 1986). While mood-congruency findings are mixed across studies with both naturally depressed and induced-depressed subjects, mood-congruent learning still offers another potential difference between natural and mood-induced depression.

Mood congruence means that some material, containing affectively valenced content, is more likely to be stored and/or recalled when one is in a particular mood. Mood congruency occurs when an affective state facilitates the learning of new information congruent with concepts already associated with that mood (Bower, 1981; Bower, 1987; Bower, Gilligan, \& Monteiro, 1981). One explanation is that mood-congruent information is supposedly more richly connected to activated nodes by nature of its shared theme and associations. This connectedness leads to a denser network of the representation of the incoming stimuli.

However, mood may not produce mood-congruent learning directly and automatically, as proposed by a simple network model of emotion. Rather, it may influence the cognitive processing of the learned material in a more complex way, depending on the specific interaction of mood, experimental task, and materials (Rinck, Glowalla, \& Schneider, 1992).

The present experiments were conducted to help clarify the source or sources of differences in previous findings obtained with induced-depressed and naturally depressed subjects. As previously stated, Ellis (1985) argued that the absence of mood effects for overall recall differences in the Hasher et al. study stemmed from a relatively weak mood state, characteristic of mild natural depression, and a task with low cognitive demands. A major requirement for the present experiments, therefore, was a recall task that demands sufficient cognitive effort to produce deficits if they exist. For our retention task, we decided to test recall of target words contained in sentences with effective or ineffective elaboration.

Elaborative information has been shown to facilitate recall when it helps to specify the relevance of target information or clarify the potential significance of target words (Stein, Littlefield, Bransford, \& Persampieri, 1984; Stevenson, 1981). However, the degree of effectiveness does not necessarily increase with sentence complexity or with the amount of congruent information. Semantically congruous phrases that do not help to specify the relevance of the target word (i.e., ineffective elaboration) and that may require greater cognitive effort, may actually impair retention and recall (Stein \& Bransford, 1979; Stein, Morris, \& Bransford, 1978).

Rather than using effectively elaborated and base sentences (cf. Ellis et al., 1984), we chose to use effective and ineffective elaborations in order to vary the degree of cognitive effort involved while retaining the amount of information presented. Therefore, a task such as effective versus ineffective elaboration-which is constant in terms of the amount of information presented but also allows the relevance of the information and the degree of cognitive effort to vary-is necessary to separate mood effects from task effects.

On the basis of the differences in mood-congruent learning effects previously mentioned, we wanted to add moodcongruent material to our sentences that would not be semantically related to the target words and that would not differentially alter the amount of information presented. We decided that by adding a single word, a descriptor, we could valence the information in either a negative or a neutral manner. This would allow us to assess any possible contextual effects of mood-congruent information (via recall of descriptors) without altering the nature of the criterion task (i.e., intentional target recall).

\section{EXPERIMENT 1}

Experiment 1 investigated the effects of natural depression on purposeful recall for target words and recall for type of descriptor (negative vs. neutral) in a secondary recall task. Descriptor words thus valenced otherwise identical sentences in the direction of presenting either negative or neutral information without altering the amount of information presented or changing the relevance of the material. Target words and descriptors were contained within semantically congruous phrases that varied in type of elaboration (effective vs. ineffective). Target words and descriptors were judged to be high-effort items due to the construction of the rest of the phrase, which did not imply, or cue, the correct word.

As previously mentioned, Ellis (1985) pointed to the use of naturally depressed subjects and a task with low cognitive effort as the reasons for the lack of a mood effect on overall recall in the Hasher et al. study. If there are no mood effects on target recall in the present study designed 
to involve high cognitive effort, then we would conclude that there are indeed important differences in the types of depression that are measured by questionnaires and those that are induced in the laboratory. A finding of mood effects on target recall would suggest that differential task demands were the source of the differences in previous findings. A similar decision rule applies to the possibility of mood effects on recall of descriptors. A failure to find an effect of mood on recall of descriptors would suggest differences between natural and induced depression. However, if naturally depressed subjects recalled more negative descriptors than did nondepressed subjects, we would conclude that differential task demands contributed to the lack of effects in the Hasher et al. experiments.

\section{Method}

Design. Three between-subject factors were varied: mood (depressed or nondepressed), descriptor valence (negative or neutral), and type of elaboration (effective or ineffective). Mood was a subject variable, and descriptor valence and type of elaboration were manipulated variables. The dependent variables of interest were the recall of target words and a secondary task involving the recall of descriptors.

Subjects. The subjects were 120 introductory psychology students at Arizona State University. They received class credit for participation. The subjects were assigned to either the depressed or nondepressed condition on the basis of BDI scores. Depressed and nondepressed subjects were randomly assigned to type of elaboration (effective or ineffective) and type of descriptor (neutral or negative).

Materials. Four sets of 25 sentences reflecting either effective or ineffective elaboration for the target word were constructed on the basis of Stein and Bransford's (1979) work. Each sentence also contained either a negative or a neutral descriptor. All sentences consisted of a base sentence with a target word that in some way described the activities of a man. Example sentences for each condition are as follows:

1. Effective Elaboration/Negative Descriptor: "The tall (target) man bought the crackers that were rotting (descriptor) high on the shelf (elaboration)."

2. Effective Elaboration/Neutral Descriptor: "The tall (target) man bought the crackers that were sitting (descriptor) high on the shelf (elaboration)."

3. Ineffective Elaboration/Negative Descriptor: "The tall (target) man bought the crackers that were rotting (descriptor) on sale (elaboration)."

4. Ineffective Elaboration/Neutral Descriptor: "The tall (target) man bought the crackers that were sitting (descriptor) on sale (elaboration)."

The base sentence presented in all conditions for testing memory of the target adjective in this example would be "The

man bought the crackers." Testing for memory of the descriptor in all conditions was conducted by presenting the entire sentence with the target adjective and descriptor missing.

Form $\mathrm{G}$ of the Depression Adjective Checklist (DACL) was completed by all subjects at the end of the experiment as a measure of their current mood state. The DACL requires subjects to check all adjectives that apply to how they are currently feeling. DACL scores have been used in several experiments as a measure of state depression (cf. Ellis et al., 1984).

Criterion measures. All subjects received the BDI (Beck, Ward, Mendelson, Mock, \& Erbaugh, 1961) as part of a larger questionnaire administered to several introductory psychology classes. Approximately 8 weeks lapsed between BDI testing and participation in the present experiment. BDI scores have been found to be relatively stable over time (Oliver \& Burkham, 1979), a reliable and valid measure for the assessment of depression (Gould, 1982; Oliver \& McGee, 1982; Reynolds \& Gould, 1981), and appropriate for use in a college population (Bumberry \& Oliver, 1978).

Cutoff scores were determined according to previously established criteria in a university population for nondepressed and mildly depressed subjects (Oliver \& Burkham, 1979; Weinman, Levin, \& Mathew, 1982). These levels were chosen in order to have a clear difference between depressed and nondepressed and to avoid extreme cases of depression. Therefore, scores between and including 10 and 16 were chosen as the range for the depressed subjects group. Scores between and including 0 and 3 were chosen as the range for the nondepressed subjects group.

Procedure. The subjects were contacted individually by telephone and invited to participate in the present experiment for class credit. Testing occurred in small groups of 8 or less. Printed instructions were given out for the subjects to read along with the experimenter. The subjects were told that they would have $4 \mathrm{~min} 10 \mathrm{sec}$ to read and study 25 sentences, and that their task was to remember the target word. They were also told that the sentences would be represented with a blank where the target word had originally appeared in a different order for testing. It was emphasized that it was important to read and study the entire sentence to help them remember the target word. However, the subjects were not informed that they would be asked to recall the descriptor words.

For the first test phase, recall of target words, the subjects received only the base sentences, with the target missing, in a different order from that used in the study phase. Because target words in all sentences were followed by the same noun (man), all targets were semantically interchangeable with all base sentences. This minimized the possibility of the subjects' guessing the correct target word in the test phase. Additionally, by presenting only the base sentences for target recall, the subjects were not able to use the elaborative clause as a cue for guessing the correct target word. The subjects were allowed $20 \mathrm{~min}$ to complete this portion of the experiment, although no one required this much time.

In the second test phase, recall of descriptor words, the subjects received complete sentences in a different order from that used in the study or first test phase with the target and descriptor words missing. The subjects were instructed to recall as many of the other descriptive words (i.e., negative or neutral) in the sentence as they could, even if they had to guess. Guessing was encouraged in order to promote reasonable efforts at recall by the depressed subjects. This phase resembled an incidental learning paradigm in that the subjects were not explicitly told to learn this material and their attention was primarily directed toward recall of the target words. The subjects were also allowed 20 min to complete this portion of the experiment. All subjects completed this phase in time.

At no time were any subjects informed that they had been selected on the basis of their previous BDI scores. It is quite possible that the subjects became aware that the study had something to do with mood; however, because we were dealing with mild cases of depression, we felt it was important not to reveal BDI scores that the subjects could misinterpret as diagnoses. Therefore, as a debriefing procedure, all subjects were informed that they had been chosen because their pattern of responses on the questionnaire indicated that they appeared to respond to novel stimuli with a greater frequency than other respondents. The subjects were told that we were attempting to construct a new scale based on these patterns. Even though the subjects were not correctly informed that they were initially chosen on the basis of BDI scores, they were told that the DACL was used to see "how they were feeling today" and that this measure would be evaluated to determine whether mood had any effects on their performance.

\section{Results}

The average BDI score was 1.67 for subjects assigned to the nondepressed condition and 12.47 for subjects in 
the depressed $\operatorname{mood}\left[F(1,118)=1,159.47, M S_{\mathrm{e}}=2.98\right.$, $p<.0001]$. The average DACL score was 6.78 for subjects assigned to the nondepressed condition and 10.6 for subjects in the depressed condition $[F(1,118)=16.60$, $\left.M S_{\mathrm{e}}=26.33, p<.0001\right]$.

Target recall. The main effect of $\operatorname{mood}[F(1,112)=$ $\left.0.19, M S_{\mathrm{e}}=23.76, p<1\right]$, the main effect of elaboration $\left[F(1,112)=0.06, M S_{\mathrm{e}}=23.76, p<1\right]$, and the main effect of descriptor type $\left[F(1,112)=1.39, M S_{\mathrm{e}}=\right.$ 23.76, $p<1$ ] were not significant. Depressed subjects recalled an average of 13.82 target words, and nondepressed subjects recalled an average of 13.44 target words. The average number of targets recalled was 13.74 for effective elaboration and 13.52 for ineffective elaboration. The average number of targets recalled was 14.15 for neutral descriptors and 13.10 for negative descriptors. The mood $\times$ elaboration interaction $[F(1,112)=0.77$, $\left.M S_{\mathrm{e}}=23.76, p<1\right]$, the elaboration $\times$ descriptor interaction $\left[F(1,112)=1.67, M S_{\mathrm{e}}=23.76, p<1\right]$, and the three-way interaction $\left[F(1,112)=2.78, M S_{\mathrm{e}}=23.76\right.$, $p<1]$ were not significant. Individual cell means are presented in Table 1.

There was a significant mood $\times$ descriptor interaction $\left[F(1,112)=4.80, M S_{\mathrm{e}}=23.76, p<.03\right]$. Nondepressed subjects recalled a greater number of target words when sentences contained neutral rather than negative descriptors (14.94 and 11.93, respectively) regardless of type of elaboration $\left[F(1,56)=5.73, M S_{\mathrm{e}}=23.55, p<\right.$ $.02]$. When neutral descriptors appeared in the higher effort ineffective elaboration condition, there was also a tendency for nondepressed subjects to recall more targets than naturally depressed subjects. It is possible that nondepressed subjects were better able to generate their own elaborations for learning ill-defined relationships in a high-effort condition than were naturally depressed subjects. This finding would support a reduced capacity model of depression (Ellis et al., 1984). Similarly, the finding that there was not a statistically significant difference in the number of target words recalled by naturally depressed and nondepressed subjects (13.54 and 13.94 , respectively) in the effective elaboration condition, requiring less cognitive effort, supports the claim that naturally occurring mild depression may not manifest any differences in tasks that are comparatively less demanding (Ellis, 1985).

Table 1

Mean Number of Target Words Correctly Recalled in the Nondepressed and Naturally Depressed Conditions

\begin{tabular}{ccc}
\hline & Nondepressed & $\begin{array}{c}\text { Naturally } \\
\text { Depressed }\end{array}$ \\
\hline Effective Elaboration & 12.60 & 12.67 \\
Negative Descriptor & 15.27 & 14.40 \\
Neutral Descriptor & & \\
Ineffective Elaboration & 11.27 & 15.87 \\
Negative Descriptor & 14.60 & 12.33 \\
Neutral Descriptor &
\end{tabular}

Note-For the nondepressed condition, $n=60$. For the naturally depressed condition, $n=60$.
In contrast, depressed subjects recalled more target words when sentences contained negative descriptors than when sentences contained neutral descriptors (14.27 and 13.37, respectively) $\left[F(1,56)=4.34, M S_{\mathrm{e}}=23.55, p<\right.$ .04]. This mood-congruent effect of descriptors on target recall was somewhat unexpected since the descriptors were not related semantically to the target words. If anything, we expected that negative descriptors might impair the retention of target words in the case of depressed subjects by diverting needed attentional resources from the criterion task.

The differential pattern of recall indicated in the twoway interaction-greater recall of targets with negative descriptors by depressed subjects (15.87) and higher recall of targets with neutral descriptors by nondepressed subjects (14.60)-was limited to sentences with ineffective elaboration. With effective elaboration, both depressed and nondepressed subjects showed a slight tendency for greater recall of targets with neutral descriptors. Regardless of type of elaboration, nondepressed subjects showed a tendency for negative descriptors to be associated with reduced retention of target words. Only with ineffective elaboration did depressed subjects show the opposite tendency: higher recall of target words with negative descriptors. The depressed subjects were able to raise their performance in the ineffective elaboration/negative descriptor condition to a level comparable to that of nondepressed subjects with effective elaboration. It is as if, given no other cues to assist retention of targets, depressed subjects were able to use negative descriptors to establish a context for elaboration that enhanced target recall.

Descriptor recall. As with target recall, the main effect of $\operatorname{mood}\left[F(1,112)=1.11, M S_{\mathrm{e}}=15.96, p<1\right]$, the main effect of elaboration $\left[F(1,112)=2.28, M S_{\mathrm{e}}=\right.$ $15.96, p<1]$, the main effect of descriptor type $\left[F(1,112)=0.47, M S_{\mathrm{e}}=15.96, p<1\right]$, and the threeway interaction $\left[F(1,112)=1.76, M S_{\mathrm{e}}=15.96, p<1\right]$ were not significant. Depressed subjects recalled an average of 6.68 descriptors; nondepressed subjects recalled an average of 5.92 descriptors. The average number of descriptors recalled was 6.85 for effective elaboration and 5.75 for ineffective elaboration. Regarding descriptor type, the average number of descriptors recalled was 6.55 in the neutral condition and 6.05 in the negative condition. Individual cell means are presented in Table 2 .

There was a significant mood $\times$ descriptor interaction for recall of descriptor words $\left[F(1,112)=4.42, M S_{\mathfrak{e}}=\right.$ $15.96, p<.04]$. Nondepressed subjects recalled significantly more neutral descriptors than negatively valenced descriptors $[6.94$ and 4.90 , respectively; $F(1,56)=4.67$, $\left.M S_{\mathrm{e}}=13.28, p<.04\right]$, although there was no significant difference between depressed and nondepressed subjects for the average number of neutral descriptors recalled. Similarly, the elaboration $\times$ descriptor interaction $\left[F(1,112)=4.81, M S_{\mathrm{e}}=15.96, p<.03\right]$ indicates that more descriptors overall were recalled with effective elaboration than with ineffective elaboration regardless of mood. 
Table 2

Mean Number of Descriptors Correctly Recalled in the Nondepressed and Naturally Depressed Conditions

\begin{tabular}{ccc}
\hline Effective Elaboration & Nondepressed & $\begin{array}{c}\text { Naturally } \\
\text { Depressed }\end{array}$ \\
Negative Desciptor & 5.80 & \\
Neutral Descriptor & 8.47 & 5.80 \\
Ineffective Elaboration & & 7.33 \\
Negative Descriptor & 4.00 & \\
Neutral Descriptor & 5.40 & 8.60 \\
\hline
\end{tabular}

Note-For the nondepressed condition, $n=60$. For the naturally depressed condition $n=60$.

Depressed subjects recalled significantly more negative descriptors than did nondepressed subjects [7.2 and 4.9, respectively, $\left.F(1,56)=5.30, M S_{\mathrm{e}}=13.28, p<.03\right]$. Again, this result was entirely dependent on the ineffective elaboration condition. The increased recall of negative descriptors by depressed subjects parallels that of increased recall for target words in this condition by depressed subjects. Nondepressed subjects, on the other hand, showed the lowest recall for target words and negative descriptors in the ineffective elaboration condition. It is as though nondepressed subjects viewed negative descriptors as distractors to the target word and purposely ignored them. Because increased recall performance by depressed subjects was specific to the ineffective elaboration/negative descriptor condition, the mood $\times$ elaboration interaction for recall of descriptors was only marginally significant $\left[F(1,112)=3.34, M S_{\mathrm{e}}=15.96, p<\right.$ .07]. This interaction indicates that recall of descriptor words by depressed subjects did not vary with type of elaboration (6.8 descriptors in ineffective elaboration and 6.57 in effective elaboration), but nondepressed subjects recalled more descriptors overall with effective (7.14) elaboration than with ineffective $(4.7)$ elaboration $[F(1,56)$ $\left.=6.69, M S_{\mathrm{e}}=13.28, p<.02\right]$.

\section{Discussion}

The purpose of Experiment 1 was to provide data that would help clarify the source of some discrepencies existent in previous studies of depression. We will organize the following discussion of Experiment 1 in terms of overall recall and mood-congruent effects.

Overall recall. Ellis has consistently demonstrated that subjects in whom depression has been induced exhibit poorer recall than do nondepressed subjects in a variety of tasks. In contrast, we found no effect of mood on target recall. Even though the use of an intentional learning paradigm may qualify the results obtained with experimentergenerated elaborations by allowing subjects the opportunity to generate their own elaborations, we feel that the absence of a main effect of mood cannot be attributed to minimum task demands and therefore to minimum cognitive effort. Our sentence construction created a difficult recall task with substantial interitem interference. The level of difficulty of the task is indicated by the average recall scores in Experiment 1 that ranged from a high of 15.87 targets $(63 \%)$ to a low of 11.27 targets $(45 \%)(25$ possible). One can compare this to other studies that have used fewer sentences (typically 10), thus reducing the interitem interference, and that have found a recall rate of $74 \%$ with experimenter-generated effective elaboration and $91 \%$ with subject-generated effective elaboration (Reed, 1988).

Our results are more supportive of Hasher's preferred explanation in that we failed to find evidence for overall reduced target recall, indicating that there may be fundamental differences in the types of depression as measured by questionnaires (e.g., the BDI) and those induced in the laboratory at least in some instances. On the basis of Ellis's resource allocation model, mildly naturally depressed subjects do not indicate diminished attentional resources in all instances.

Mood congruence. Two types of mood-congruent effects were found in Experiment 1: one for recall of target words, and the other for descriptors in the secondary recall task. Naturally depressed subjects recalled more negative descriptors than did nondepressed subjects. Naturally depressed subjects recalled more target words in sentences with negative descriptors than in sentences with neutral descriptors; nondepressed subjects showed the opposite pattern. However, the tendency for depressed subjects to recall more targets in sentences with negative descriptors was limited to the condition with ineffective elaboration. When presented with effective elaboration, which is a less cognitively demanding task, their performance was quite similar to that of the nondepressed subjects. This pattern is also consistent with the majority of findings in studies of mood-congruent recall with induceddepressed subjects (e.g., Blaney, 1986). Our results suggest that the failure of Hasher et al. to find moodcongruent effects may not have resulted from the use of naturally depressed subjects, but may instead be due to the operation of some alternative factor.

The facilitating effects of negative descriptors for depressed subjects would also seem to explain the absence of a main effect of elaboration. Both types of sentences were judged to require high cognitive effort; however, effective elaboration specified the relevance of target words, and ineffective elaboration did not. Consequently, the encoding demands of the two tasks varied and should have produced a main effect for elaboration. However, it would appear that an effect of elaboration was masked by the effect of descriptors on target recall. Our results indicate that, for depressed subjects, negatively valenced information may facilitate recall of material unrelated to the particular mood-congruent stimuli by providing a contextual framework for generating effective elaborations. This process appears to occur even though task instructions should have focused the attention of all subjects toward the recall of target words. Perhaps mood-congruent strategies are more natural and effective than typical elabora- 
tion for depressed subjects, whereas the more "effective" elaborative strategy is more efficient for nondepressed subjects.

Although the effect of descriptors might have masked elaboration effects (as previously mentioned), another possibility is that the construction of the sentences was inadequate to produce effects in the predicted direction. To examine this possibility, the same stimulus set, with descriptive clauses removed, was readministered in a group setting to 106 introductory psychology students. We assumed that if we found a main effect of elaboration, then we could attribute the previous failure to find an effect of elaboration to the presence of descriptors. Alternatively, a null finding would suggest an ineffective manipulation. We found that without the presence of descriptors the effects of type of elaboration were in accordance with the previous findings of Stein and Bransford (1979). Subjects in the effective elaboration condition recalled an average of 15.2 target words; subjects in the ineffective elaboration condition recalled an average of 11.1 target words. This difference is statistically reliable $[F(1,104)=$ $\left.12.03, M S_{\mathrm{e}}=38.3, p<.001\right]$, and we can conclude that the lack of a main effect for elaboration was not due to the construction of the stimulus set. Thus, the results suggest that the valence of descriptors within the sentence exerts differential recall effects depending on mood. These findings introduce the possibility that naturally depressed subjects may be able to utilize negatively valenced descriptors to assist in target recall in the absence of effective elaboration.

\section{EXPERIMENT 2}

Now we return to the question motivating the first experiment. That is, do the differences in the findings of Hasher et al. (1985), on the one hand, and Ellis (1985), on the other, reflect differences in types of depression (natural or induced) or in the nature of certain task requirements? Experiment 2 was essentially a replication of Experiment 1 , except that mood was a manipulated variable rather than a subject variable as in Experiment 1. Examination of performances of depressed subjects in Experiments 1 and 2 will permit a comparison between types of depression, natural or induced, not confounded with task differences.

We chose to conduct two separate experiments instead of a single experiment combining natural and induced depression for two reasons. First, because the nondepressed group in Experiment 1 indicated reduced recall for targets in the presence of negative descriptors and reduced recall of negative descriptors (particularly in the ineffective elaboration condition), we wanted the opportunity to replicate these unusual findings. Second, given the status of our subject pool, it would have been necessary to reduce the number of subjects in each cell if we ran all groups concurrently.

\section{Method}

Design. The design of Experiment 2 was identical to that of Experiment 1 with the exception that we now manipulated mood. The subjects were randomly assigned to either a depressed mood manipulation condition or a neutral mood condition.

Subjects. The subjects were chosen from 160 introductory psychology students selected for possible mood induction. They received course credit for their participation. As in Experiment 1, all subjects had completed a larger questionnaire containing the BDI. Only subjects who scored 9 or less on the BDI were eligible. Thirtytwo subjects were eventually excluded from the analyses for excessively high (two standard deviations) pre- and/or post-DACL scores. The subjects were randomly assigned to the two conditions.

Materials. A modified Velten (Siebert \& Ellis, 1991) was used for inducing depression. Ten sentences from the Velten were used for a happy mood induction at the end of the experiment. The same stimulus sentences for manipulation of elaboration and descriptor valence used in Experiment 1 were used in Experiment 2.

Procedure. The subjects were tested in groups of 5 or less in single sessions lasting about $1 \mathrm{~h}$. First, for subjects in the depressed mood group, the process of mood induction was explained, and verbal consent for participation was obtained. The mood-inducing sentences were studied for $20 \mathrm{sec}$ each. The subjects were informed that this procedure was designed to induce a temporary state of depression through a process similar to free association, and that they were to try and maintain whatever mood they originally achieved throughout the duration of the experiment. The subjects then completed a DACL before proceeding on to the next phase.

The subjects in the neutral mood condition began the experiment by filling out a DACL. All subjects were then read instructions identical to those used in Experiment 1, and then they completed an identical task. The subjects in both conditions then completed another form of the DACL. The subjects in the depressed mood condition received the happy mood induction and were questioned for any residual depressive effects. No subjects complained of continuing feelings of depression. They were then released from the study. The subjects were debriefed in a manner similar to that used in Experiment 1.

\section{Results}

The average DACL score was 16.89 for induced-mood subjects after mood induction and 7.66 for nondepressed subjects. The difference was statistically reliable $[F(1,126)$ $\left.=158.41, M S_{\mathrm{e}}=9.02, p<.001\right]$. No differences were found between pre- and post-DACL testing for either group. This is an important temporal consideration when assessing mood-related performance across various tasks because a significant loss of mood over the duration of the experiment would seriously damage the interpretation of results.

Target recall. In contrast to the results of Experiment 1 , all three main effects (i.e., mood, elaboration, and descriptor) were signficant in Experiment 2. Nondepressed subjects recalled more target words than did induced-depressed subjects $[13.75$ and 11.92 , respectively; $\left.F(1,120)=4.87, M S_{\mathrm{e}}=21.97, p<.03\right]$. More target words were recalled with effective elaboration than with ineffective elaboration [14.16 and 11.52 , respectively; $F(1,120)=10.16, M S_{\mathrm{e}}=21.97, p<.002$ ]. Significantly more target words were recalled when sentences contained neutral descriptors than when sentences contained negative descriptors [ 14.27 and 11.41 , respectively; 
Table 3

Mean Number of Target Words Correctly Recalled in the Nondepressed and Induced-Depressed Conditions

\begin{tabular}{ccc} 
& Nondepressed & $\begin{array}{c}\text { Induced } \\
\text { Depressed }\end{array}$ \\
\hline Effective Elaboration & & \\
Negative Descriptors & 15.50 & 11.38 \\
Neutral Descriptors & 15.69 & 14.06 \\
Ineffective Elaboration & & \\
Negative Descriptors & 9.25 & 9.50 \\
Neutral Descriptors & 14.56 & 12.75 \\
\hline
\end{tabular}

Note-For the nondepressed condition, $n=64$. For the induceddepressed condition, $n=64$.

$\left.F(1,120)=11.91, M S_{\mathrm{e}}=21.97, p<.001\right]$. Individual means for all cells are presented in Table 3.

Again, in contrast to the findings obtained in Experiment 1 , none of the higher order interactions for target recall in Experiment 2 were significant: mood $\times$ elaboration $\left[F(1,120)=1.60, M S_{\mathrm{e}}=21.97, p<1\right], \operatorname{mood} \times$ descriptor type $\left[F(1,120)=0.02, M S_{\mathrm{e}}=21.97 ; p<1\right]$, and elaboration $\times$ descriptor $\left[F(1,120)=2.95, M S_{\mathrm{e}}=\right.$ 21.97, $p<.10]$.

Descriptor recall. The only significant effect in Experiment 2 for incidental recall of descriptors was a main effect of elaboration. This effect showed that more descriptors were recalled with effective elaboration than with ineffective elaboration [6.34 and 3.81 , respectively; $\left.F(1,120)=18.17, M S_{\mathrm{e}}=11.28 ; p<.001\right]$. Neither the main effect for mood $\left[F(1,120)=0.71, M S_{\mathrm{e}}=11.28\right.$, $p<1]$, nor the main effect for descriptor type $[F(1,120)$ $=2.84, M S_{\mathrm{e}}=11.28, p<.09 \mathrm{~J}$ were significant. The same was true for the higher order interactions: $\operatorname{mood} x$ elaboration $\left[F(1,120)=0.03, M S_{\mathrm{e}}=11.28, p<1\right]$, mood $\times$ descriptor type $\left[F(1,120)=2.49, M S_{\mathrm{e}}=11.28\right.$, $p<1]$, and elaboration $\times$ descriptor type $[F(1,120)=$ $\left.0.02, M S_{\mathrm{e}}=11.28, p<1\right]$.

\section{Discussion}

The main effects of mood and elaboration observed in Experiment 2 are in accord with the results of Ellis and his colleagues. Interestingly, in light of the results of Experiment 1 , there was no differential effect of type of descriptor on target recall for depressed and nondepressed subjects. Both groups of subjects in Experiment 2 tended

Table 4

Mean Number of Descriptor Words Correctly Recalled in the Nondepressed and Induced-Depressed Conditions

\begin{tabular}{ccc} 
& Nondepressed & $\begin{array}{c}\text { Induced } \\
\text { Depressed }\end{array}$ \\
\hline Effective Elaboration & 5.25 & \\
Negative Descriptor & 6.94 & 6.38 \\
Neutral Descriptor & & 6.75 \\
Ineffective Elaboration & 2.44 & 4.19 \\
Negative Descriptor & 4.63 & 3.94 \\
Neutral Descriptor & &
\end{tabular}

Note-For the nondepressed condition, $n=64$. For the induceddepressed condition, $n=64$. to recall more target words in sentences containing neutral descriptors than in sentences containing negative descriptors. This was the same pattern shown by nondepressed subjects in Experiment 1. Another surprising finding, again in light of the findings in Experiment 1, was the absence of either a mood main effect or any interactions with mood on recall of descriptors.

In the introduction to Experiment 2, we mentioned that close similarity of results in Experiments 1 and 2 would suggest commonality in the information processing abilities and/or strategies of induced-depressed and naturally depressed subjects. Dissimilarity in the results across the two experiments, on the other hand, would indicate differences in the information processing abilities of individuals who are naturally depressed and those whose depression is induced in the laboratory. The results of Experiments 1 and 2 point to differences in the performances of natural and induced depression.

\section{GENERAL DISCUSSION}

Comparing the results of Experiments 1 and 2, there were clear differences in the recall of naturally depressed (Experiment 1) and induced-depressed (Experiment 2) subjects. These differences were observed in both overall level of recall of target words and mood-congruent effects in recall of target words and descriptors. Naturally depressed subjects showed no overall deficit in intentional recall of target words relative to nondepressed subjects, whereas induced-depressed subjects exhibited poorer recall than did nondepressed subjects. Both types of findings in the literature-no overall recall deficit with natural depression (Hasher et al., 1985) and deficits with induced depression (Ellis et al., 1984)-were reproduced in the present experiments. This is an important finding, since differences cannot be ascribed to differential task demands-the task was the same for both groups. The present results on overall recall are consistent with Ellis's suggestion that the effects of mild natural depression might be too weak to have any evident effects on recall. The results also support Ellis's (1985) proposal that naturally depressed subjects do not evidence recall deficits in relatively undemanding tasks (e.g., effective elaboration). In a higher effort task (e.g., ineffective elaboration/neutral descriptors), naturally depressed subjects did show a tendency toward reduced recall relative to nondepressed subjects, although this result was not statistically significant. It is quite possible that the use of an intentional learning paradigm qualified these results, and an incidental learning task should be conducted before interpreting these results further.

Although induced-depressed subjects did score higher on the DACL than did naturally depressed subjects, one must be careful in interpreting this as evidence for differences in intensity of mood. Naturally depressed subjects were not aware that their participation directly involved mood state. Because induced-depressed subjects were aware of this, a certain degree of subject compli- 
ance may be expected. In fact, many of the experiments that do find memory deficits in depressives' performance have induced mood. It may be that mood-induction procedures cause brief intense levels of depression that are capable of reducing the available capacity enough to produce deficits in recall, whereas naturally occurring depression may be too mild to have any significant effects.

We found two different types of mood-congruent effects with naturally and induced-depressed subjects; however, in this case, the effects were in the opposite direction to those indicated in the studies motivating the present research. We found mood-congruent effects with naturally depressed subjects (contrary to Hasher et al., who found no effects), and we did not find any evidence for mood-congruent effects with induced-depressed subjects. Naturally depressed subjects in our study did not show increased recall for negative versus neutral descriptors. What they did show was improved recall for negative descriptors with respect to nondepressed subjects. This indicates that naturally depressed individuals may be capable of spontaneously employing negatively valenced contextual information in a recall task even where attention is specifically directed toward an unrelated target word.

The results presented so far indicate that providing mood-congruent stimuli as contextual information (i.e., negatively valencing the sentence) can exert differential effects on target recall depending on mood type. Therefore, it may be that only stable and inherent characteristics of depression are amenable to this type of activation and inducing depression is not effective in mimicking this type of subtle processing.

In contrast, induced-depressed subjects, like nonderessed subjects, did not make use of negatively valenced material for target word recall. Rather, they performed in accordance with previous findings by Ellis et al. (1984), in which nondepressed subjects performed better overall than did induced-depressed subjects, and effective elaboration produced better recall than did ineffective elaboration.

Finding inconsistency in the mood and memory literature is certainly not difficult. Taken separately, all of the mood effects reported here have appeared previously in the literature (see Singer \& Salovey, 1988). What is unusual about the present experiments is that performances of naturally depressed and induced-depressed subjects were compared in the same task and that both overall recall differences and mood-congruent effects were measured. What is also uncommon about the results is the seeming separation or dissociation of overall recall differences and mood-congruent effects in the two depressed populations. We know of no other study in which this pattern has been observed.

As noted, performance differences may occur due to the type of depression being considered. Additionally, even across nondepressed subjects, the presence or absence of descriptors appears to exert differential effects on target recall. Also, main effects of elaboration reliably occurred only for descriptor recall with induceddepressed and nondepressed subjects. It is possible that nondepressed and induced-depressed subjects viewed negative descriptors as distractors and chose to ignore them in order to more fully focus on the target item. Target and descriptor recall were highly similar for induceddepressed and nondepressed subjects, but because only a single condition (ineffective elaboration/negative descriptor) distinguished the performance of naturally depressed from induced and nondepressed subjects, it must be concluded that it may be misleading to compare performance differences across subjects.

We can also conclude that many observed differences may be highly task dependent. For example, in the absence of negative descriptors, there is a tendency for naturally depressed and induced-depressed subjects to recall more target words with effective elaboration than with ineffective elaboration. But in the negative descriptor and ineffective elaboration condition, opposite effects were observed in which naturally depressed subjects recalled the most targets, while induced and nondepressed subjects in both experiments recalled the fewest.

The differences between the performances of naturally depressed and induced-depressed subjects in the present experiments are not consistent with any current model or view we are aware of in which these two populations differ on a single dimension. While the pattern of results in the present study does not compel any particular single theoretical approach in distinguishing between properties of measured and induced depression, it does suggest the direction in which future empirical studies should occur. For example, if the mood states of the two groups are held to differ solely in intensity, the present study suggests important qualitative differences between the two types of depression. That is, with greater intensity in induced depression, we would expect stronger mood effects from all manipulations with the induced-depressed group. As noted above, that is not what we found. Also, a more precise definition of high-versus low-effort tasks is required to determine what properties of the task produce differences in cognitive effort expenditure between different types of depression. Further comparisons between induced-depressed and naturally depressed individuals will be helpful in identifying which aspects of depression are reproducible in the laboratory and which aspects are seemingly inherent only to natural depression.

\section{REFERENCES}

Baddeley, A. (1990). Human memory. Boston: Allyn \& Bacon. Beck, A. T., Ward, C. H., Mendelson, M., Mock, J., \& Erbaugh, J. (1961). An inventory for measuring depression. Archives of General Psychiatry, 4, 53-63.

Blaney, P. H. (1986). Affect and memory: A review. Psychological Bulletin, 99, 229-246.

Bower, G. H. (1981). Mood and memory. American Psychologist, 36, 129-148.

BOWER, G. H. (1987). Commentary on mood and memory. Behavior Research \& Therapy, 25, 443-455

Bower, G. H., Gilligan, S. G., \& Monteiro, K. P. (1981). Selectivity of learning caused by affective states. Journal of Experimental Psychology: General, 110, 451-473.

BumberRy, W., \& Oliver, J. M. (1978). Validation of the Beck depression inventory in a university population using psychiatric estimate 
as the criterion. Journal of Consulting \& Clinical Psychology, 46, $150-155$.

Challis, B. H., \& Krane, R. V. (1988). Mood induction and the priming of semantic memory in a lexical decision task: Asymmetric effects of elation and depression. Bulletin of the Psychonomic Society, 26, 309-312.

ClaRK, D. M. (1983). On the induction of depressed mood in the laboratory: Evaluation and comparison of the Velten and musical procedures. Advances in Behavioral Research \& Therapy, 5, 27-49.

Ehrlichman, H., \& HALPERN, J. N. (1988). Affect and memory: Effects of pleasant and unpleasant odors on retrieval of happy and unhappy memories. Journal of Personality \& Social Psychology, $\mathbf{5 5}$ 769-779.

ELLIS, H. C. (1985). On the importance of mood intensity and encoding demands in memory: Commentary on Hasher, Rose, Zacks, Sanft, and Doren. Journal of Experimental Psychology: General, 114, 392-395.

Elcus, H. C. (1990). Depressive deficits in memory: Processing initiative and resource allocation. Joumal of Experimental Psychology: General, 119, 60-62.

Ellis, H. C., \& HUNT, R. R. (1989). Fundamentals of human memory and cognition (4th ed.). Dubuque, IA: W. C. Brown.

Ellis, H. C., Seibert, P. S., \& Herbert, B. J. (1990). Mood state effects on thought listing. Bulletin of the Psychonomic Society, 28, 147-150.

Ellis, H. C., Thomas, R. L., McFarland, A. D., \& Lane, W. (1985). Emotional mood states and retrieval in episodic memory. Journal of Experimental Psychology: Learning, Memory, \& Cognition, 11, 363-370.

Eluis, H. C, , Thomas, R. L., \& Rodriguez, I. A. (1984). Emotional mood states and memory: Elaborative encoding, semantic processing, and cognitive effort. Journal of Experimental Psychology: Learning, Memory, \& Cognition, 10, 470-482.

Goodwin, A. M., \& Williams, J. M. G. (1982). Mood induction research-Its implications for clinical depression. Behavior Research \& Therapy, 20, 373-382.

Gotlib, I. H., \& McCanN, C. D. (1984). Construct accessibility and depression: An examination of cognitive and affective factors. Journal of Personality \& Social Psychology, 47, 427-439.

Gould, J. (1982). A psychometric investigation of the standard and short form Beck depression inventory. Psychological Reports, 51 $1167-1170$

Hasher, L., Rose, K. C., Zacks, R. T., Sanft, S., \& Doren, B. (1985). Mood, recall, and selectivity effects in normal college students. Journal of Experimental Psychology: General, 114, 106-120.

Kahneman, D. (1973). Attention and effort. Englewood Cliffs, NJ: Prentice-Hall.

Kenealy, P. M. (1986). The Velten mood induction procedure: A methodological review. Motivation \& Emotion, 10, 315-335.

Lazarus, R. S. (1982). Thoughts on the relations between emotion and cognition. American Psychologist, 37, 1019-1024.

Leight, K. A., \& Ellis, H. C. (1981). Emotional mood states, strategies, and state-dependency in memory. Journal of Verbal Learning \& Verbal Behavior, 20, 251-266.

Oliver, J. M., \& BURKhaM, R. (1979). Depression in university stu- dents: Duration, relation to calendar time, prevalence, and demographic correlates. Journal of Abnormal Psychology, 88, 667-670.

Oliver, J. M., \& McGeE, J. (1982). Cognition as a function of depression in a student population: Content and complexity of cognitions. Cognitive Therapy \& Research, 6, 275-286.

Pietromonaco, P. R., \& Markus, H. (1985). The nature of negative thoughts in depression. Journal of Personality \& Social Psychology, 48. $799-807$.

Polivy, J. (1981). On the induction of emotion in the laboratory: Discrete moods or multiple affect states. Journal of Personality \& Social Psychology, 41, 803-817.

PruitT, S. D., \& Ferraro, D. P. (1989). An investigation of a video mood induction procedure using multimodal assessment. Paper presented at the meeting of the American Psychological Association, New Orleans, LA.

ReEd, S. K. (1988). Cognition: Theory and applications (2nd ed.). Pacific Grove, CA: Brooks/Cole.

REYNOLDS, W. M., \& Gould, J. W. (1981). A psychometric investigation of the standard and short form Beck depression inventory. Journal of Consulting \& Clinical Psychology, 49, 306-307.

Rinck, M., Glowalla, V., \& Schneider, K. (1992). Mood congruent and mood incongruent learning. Memory \& Cognition, 20, 29-39.

SeiberT, P. S., \& Ellis, H. C. (1991). A convenient self-referencing mood induction procedure. Bulletin of the Psychonomic Society, 29, $121-124$

Singer, J. A., \& Salovey, P. (1988). Mood and memory: Evaluating the network theory of affect. Clinical Psychology Review, 8, 211-251.

Sirota, A. D., Schwartz, G. E., \& Kristeller, J. L. (1987). Facial muscle activity during induced mood states: Differential growth and carry-over of elated versus depressed patterns. Psychophysiology, 24, 691-699.

Stein, B. S., \& Bransford, J. D. (1979). Constraints on effective elaboration: Effects of precision and subject generation. Journal of Verbal Learning \& Verbal Behavior, 18, 769-777.

Stein, B. S., Littlefield, I., Bransford, J. D., \& Persampieri, M. (1984). Elaboration and knowledge acquisition. Memory \& Cognition, 12, 522-529.

Stein, B. S., Morris, C. D., \& Bransford, J. D. (1978). Constraints on effective elaboration. Journal of Verbal Learning \& Verbal Behavior, 17, 707-714.

Stevenson, R. J. (1981). Depth of comprehension, effective elaboration, and memory for sentences. Memory \& Cognition, 9, 169-176.

Sutherland, G., Newman, B., \& Rachman, S. (1982). Experimental investigations of the relations between mood and intrusive, unwanted cognitions. British Journal of Medical Psychology, 55, 127-138.

VELTEN, E. (1968). A laboratory task for induction of mood states. Be havior Research \& Therapy, 6, 473-482.

Weinman, M. L., Levin, B. L., \& Mathew, R. J. (1982). Use of psychological testing in symptom detection in a normal population. Psychological Reports, 50, 499-504.

(Manuscript received November 9, 1992;

revision accepted for publication July 9,1993 .) 